\title{
FACTOR THAT IS RELATED TO PALLIATIVE CARE ON PATIENT TERMINAL AT SITI KHADIJAH ISLAMIC HOSPITAL PALEMBANG IN 2015
}

\author{
Mardiah, Mina Marlina \\ STIK Siti Khadijah Palembang
}

\begin{abstract}
From result in medical record at Siti Khadijah Islamic Hospital Palembang in 2013 the died patient of amount 501 people while on 2014 in rise 610 people caused by terminal illness. The patient terminal have to get his palliative care that is to relieve symptoms of disease and improve the quality of life for the patient as well as the handling of pain and other issues such as physical, psychosocial and spiritual. The purpose of this research is to know the relationship between physical factors, social support, and spiritual support to palliative care to patients at Siti Khadijah Islamic Hospital Palembang. The method of this is quantitative with survey analytic through cross sectional approach. The total sample of this study 38 respondents by using the total population. The questionnaire was used to collect the data. The Chi-Square statistic was used in this study, analysis the data used by univariate and bivariate. From statistic test found that there are a correlation among physical factors in palliative care with $p$ value $0,005<\alpha(0,05)$, a correlation among social support in palliative care with $p$ value $0,018<\alpha(0,05)$, a correlation among spiritual support in palliative care with $p$ value $0,028<\alpha(0,05)$. To Siti Khadijah Islamic Hospital Palembang hope that inputed and judgment in do measure leadership care most to patients terminal.
\end{abstract}

Keyword: Physical factors, social support, spiritual support, palliative care 


\section{PENDAHULUAN}

Menurut WHO (2010) kematian adalah sesuatu yang tidak bisa dihindari oleh manusia, namun demikian kematian juga merupakan salah satu indikator mutu pelayanan kesehatan yang penting. World Health Organization (WHO) menyatakan bahwa dari tahun 20052010 diperkirakan terdapat 850 kematian per 100.000 penduduk yang terjadi setiap tahunnya (Pradana, 2011).

Berdasarkan data Departemen Kesehatan RI (2012) Pada tahun 2011, Myanmar memiliki Angka Kematian Kasar tertinggi di kawasan ASEAN, dengan 8,5 per 1.000 penduduk. Sementara Angka kematian terendah dimiliki oleh Brunei Darussalam dengan 3,3 kematian per 1.000 penduduk. Pada tahun 2011, di Indonesia terdapat 7 kematian per 1.000 penduduk. Di kawasan ASEAN, Indonesia menduduki peringkat ke-7 terendah Angka Kematian Kasar (Depkes RI, 2012).

Angka Kematian Kasar (AKK) Provinsi Sumatera Selatan berdasarkan estimasi pada tahun 2011 sebesar 22,2 per 1000 penduduk, menurun menjadi 21,8 per 1000 penduduk pada tahun 2012, kemudian menurun lagi menjadi 21,4 per 1000 penduduk (Dinkes Sumsel, 2012)

Terdapat beberapa penyebab kematian adalah kondisi kronis seperti penyakit-penyakit yang tergolong dalam "terminal illness" yaitu penyakit jantung, stroke, dan lemahnya pernafasaan. Pada kenyataannya, penyakit jantung, kanker, dan stroke terhitung enam puluh persen yang menyebabkan kematian di Amerika Serikat. Hal ini sejalan dengan yang ada di Indonesia, penyakit-penyakit yang tergolong ke dalam terminal illness seperti penyakit jantung koroner, stroke, diabetes, merupakan faktor utama penyebab kematian di Indonesia (Sutrisno, 2007).

Menurut White (2002) penyakit terminal (Terminal illness) merupakan penyakit progresif yaitu penyakit yang menuju kearah kematian. Penyakit terminal ini dapat dikatakan harapan untuk hidup tipis, tidak ada lagi obat-obatan, tim medis sudah give up atau menyerah (Cemy, 2010).

Pada stadium lanjut, pasien dengan penyakit kronis mengalami berbagai masalah fisik seperti nyeri, sesak nafas, penurunan berat badan, gangguan aktivitas yang mempengaruhi kualitas hidup dan keluarganya. Kebutuhan pasien pada stadium lanjut atau suatu penyakit tidak hanya pemenuhan/pengobatan gejala fisik, namun juga pentingnya dukungan terhadap kebutuhan psikologis, sosial, dan spiritual yang dilakukan dengan pendekatan interdisiplin yang dikenal dengan perawatan paliatif (Doyle \& Macdonald, 2003: 5 dalam Cemy, 2010).

Perawatan paliatif adalah pendekatan yang bertujuan memperbaiki kualitas hidup pasien dan keluarga yang menghadapi masalah yang berhubungan dengan penyakit yang dapat mengancam jiwa, melalui pencegahan dan peniadaan melalui identifikasi dini dan penilaian yang tertib serta penanganan nyeri dan masalah-masalah lain, fisik, psikososial dan spiritual (Kepmenkes RI No: 812, 2007).

Berdasarkan hasil penelitian Pradana (2010), setelah dilakukan pengukuran kebutuhan perawatan paliatif pada responden, diperoleh responden dengan kebutuhan perawatan paliatif rendah sebanyak 14 orang $(16,5 \%)$, sedang sebanyak 65 orang $(76,5 \%)$, dan tinggi sebanyak 6 orang $(7,1 \%)$. 
Dari hasil pengambilan data awal yang dilakukan di Rumah Sakit Islam Siti Khadijah Palembang dua tahun terakhir ini 2013 sampai dengan 2014, jumlah pasien yang meninggal dari bulan Januari sampai Desember tahun 2013 berjumlah 501 orang dikarenakan pasien menderita penyakit stroke dan hipertensi. Sedangkan pada tahun 2014 jumlah pasien yang meninggal berjumlah 610 orang dikarenakan pasien menderita penyakit Stroke hemorrhagic, Edema paru dan Pneumonia.

Berdasarkan latar belakang di atas peneliti berkeinginan untuk mengadakan penelitian tentang faktor-faktor yang berhubungan dengan perawatan paliaif pasien kondisi terminal di Rumah Sakit Siti Khadijah Palembang Tahun 2015.

\section{METODE PENELITIAN}

Jenis penelitian ini adalah kuantitatif dengan menggunakan metode survey analitik melalui pendekatan cross sectional. Rancangan penelitian cross sectional adalah suatu penelitian yang semua variabelnya, baik variabel dependen maupun variabel indevenden yang diobservasi sekaligus dalam waktu yang sama (Notoadmodjo, 2012).

Populasi yang digunakan dalam penelitian ini adalah semua perawat di ruangan Intensive Care Unit dan ruangan Penyakit Dalam yang berjumlah 38 orang.

Sampel dalam penelitian ini adalah seluruh populasi dijadikan sampel semua perawat yang bertugas diruangan ICU dan ruang penyakit dalam RSI Siti Khadijah Palembang tahun 2015. Teknik pengambilan sampel menggunakan Total Populasi.

Dengan kriteria inklusi:

1) Perawat yang bersedia menjadi responden
2) Semua perawat yang bertugas di ruangan Intensive Care Unit dan ruangan Penyakit Dalam

3) Perawat yang pegawai tetap atau tenaga kontrak

Sedangkan kriteria eksluksi:

1) Perawat yang sedang menjalani cuti

2) Perawat yang sedang melanjutkan studi

3) Perawat yang ditugaskan di luar negeri Pengumpulan Data

1) Data Primer

Data primer penelitian ini dilakukan langsung dari responden dengan menyebarkan kuesioner.

2) Data Sekunder

3) Data sekunder penelitian ini diperoleh dari rekam medis.

Tehnik Pengolahan Data

1) Editing (Pengumpulan Data)

Pada tahap ini, hasil isian dari kuisioner dilakukan pengecekan dan pengkoreksian data yang dikumpulkan karena kemungkinan data yang masuk atau data yang dikumpulkan tidak logis atau meragukan.

2) Coding (Pengkodean)

Pada tahap ini kuisioner dilakukan penyuntingan dengan cara memberikan "kode" atau "coding" yakni mengubah data berbentuk kalimat atau huruf menjadi data angka atau bilangan. Dalam penelitian ini peneliti menggunakan coding (pengkodean) nya sebagai berikut:

Kode $1=$ Tidak, Kode $2=$ Ya Nilai median didapat dari hasil pengolahan data dengan menggunakan komputerisasi dari hasil observasi yang telah dilakukan oleh peneliti dengan melihat test normality karena data tidak terdistribusi normal. 
3) Data Entry (Memasukan Data)

Jawaban-jawaban dari masing-masing responden yang dalam dimasukan kedalam program komputer untuk pemprosesan dengan menggunakan komputerisasi.

4) Cleaning Data (Pembersihan Data)

Data yang telah dimasukan, kemudian di periksa kembali sesuai dengan kriteria dan yakin bahwa data yang telah masuk benarbenar bebas dari kesalahan.

cara meng-entry data dari kuisioner ke paket program komputer.

1) Cleaning (Membersihkan Data)

Pada tahap ini dilakukan kegiatan pengecekan kembali data yang sudah di entry apakah ada kesalahan atau tidak.

Data dalam penelitian ini, di analisis melalui:

1) Analisis Univariat

Analisa Univariat dilakukan dengan distribusi frekuensi dari masing-masing variabel dependen dan independen.

2) Analisis Bivariat

Analisa Bivariat Bertujuan untuk melihat hubungan antara variabel independen analisa statistik secara bivariat pada penelitian ini menggunakan uji $x^{2}$ atau uji kai kuadrat (Chi Square test) secara statistik dianggap bermakna jika nilai $p<0,05$.

\section{HASIL PENELITIAN}

\section{Analisa Univariat}

1. Perawatan Paliatif pada Pasien Terminal

Tabel 5.1 Distribusi frekuensi Berdasarkan Perawatan Paliatif

\begin{tabular}{ccc}
\hline $\begin{array}{c}\text { Perawatan } \\
\text { Paliatif }\end{array}$ & Jumlah & Persentasi \\
\hline Baik & 25 & $65.8 \%$ \\
\hline Kurang & 13 & $34.2 \%$ \\
\hline Total & 38 & 100.0 \\
\hline
\end{tabular}

Dari tabel 5.1 diketahui bahwa perawatan paliatif yang baik yaitu sebanyak 25 responden $(65,8 \%)$ lebih besar dibandingkan dengan perawatan paliatif yang kurang baik yaitu sebanyak 13 responden (34,2\%).

\section{Faktor Fisik}

Tabel 5.2 Distribusi frekuensi Berdasarkan Faktor Fisik

\begin{tabular}{ccc}
\hline Faktor Fisik & Jumlah & Persentasi \\
\hline Baik & 22 & $57,9 \%$ \\
\hline Kurang & 16 & $42,1 \%$ \\
\hline Total & 38 & 100.0 \\
\hline
\end{tabular}

Dari tabel 5.2 diketahui bahwa faktor fisik yang baik yaitu sebanyak 22 responden (57,9\%) lebih besar dibandingkan dengan faktor fisik yang kurang baik yaitu sebanyak 16 responden $(42,1 \%)$.

3. Dukungan Sosial

Tabel 5.3 Distribusi frekuensi Berdasarkan Dukungan Sosial

\begin{tabular}{ccc}
\hline $\begin{array}{c}\text { Dukungan } \\
\text { Sosial }\end{array}$ & Jumlah & Persentasi \\
\hline Baik & 23 & $60,5 \%$ \\
\hline Kurang & 15 & $39,5 \%$ \\
\hline Total & 38 & 100.0 \\
\hline
\end{tabular}

Dari tabel 5.3 diketahui bahwa dukungan sosial yang baik yaitu sebanyak 23 responden $(60,5 \%)$ lebih besar dibandingkan dengan dukungan sosial yang kurang baik yaitu sebanyak 15 responden (39,5\%). 
4. Dukungan Spiritual

Tabel 5.4 Distribusi frekuensi Berdasarkan Dukungan Spiritual

\begin{tabular}{ccc}
\hline $\begin{array}{c}\text { Dukungan } \\
\text { Spiritual }\end{array}$ & Jumlah & Persentasi \\
\hline Baik & 25 & $65.8 \%$ \\
\hline Kurang & 13 & $34.2 \%$ \\
\hline Total & 38 & 100.0 \\
\hline
\end{tabular}

\section{Analisa Bivariat}

1. Hubungan Antara Faktor Fisik Perawat dengan Perawatan Paliatif
Dari tabel 5.4 diketahui bahwa dukungan spiritual yang baik yaitu sebanyak 25 responden $(65,8 \%)$ lebih besar dibandingkan dengan dukungan spiritual yang kurang baik yaitu sebanyak 13 responden $(34,2 \%)$.

Tabel 5.5 Hubungan Antara Faktor Fisik dengan Perawatan Paliatif pada Pasien Terminal

\begin{tabular}{|c|c|c|c|c|c|c|c|c|}
\hline \multirow{3}{*}{ Faktor Fisik } & \multicolumn{4}{|c|}{ Perawatan Paliatif } & \multirow{2}{*}{\multicolumn{2}{|c|}{ Total }} & \multirow{3}{*}{$\begin{array}{c}P \\
\text { Value }\end{array}$} & \multirow{3}{*}{ OR } \\
\hline & \multicolumn{2}{|c|}{ Baik } & \multicolumn{2}{|c|}{ Kurang } & & & & \\
\hline & $\mathrm{n}$ & $\%$ & $\mathrm{n}$ & $\%$ & $\mathrm{n}$ & $\%$ & & \\
\hline Baik & 19 & 86,4 & 3 & 13,6 & 22 & 100 & 0,005 & 10,556 \\
\hline \multirow[t]{2}{*}{ Kurang } & 6 & 37,5 & 10 & 62,5 & 16 & 100 & & \\
\hline & 25 & & 13 & & 38 & & & \\
\hline
\end{tabular}

Berdasarkan tabel 5.5 diatas dapat diketahui bahwa responden yang memberikan faktor fisik baik dan melakukan perawatan paliatif secara baik sebanyak 19 responden $(86,4 \%)$ dari 22 responden sedangkan responden yang memberikan faktor fisik kurang baik dan melakukan perawatan paliatif secara baik sebanyak 6 responden $(37,5 \%)$ dari 16 responden.

Hasiluji statistik didapatkan $p$ value 0,005

$<a=0,05$ menunjukkan bahwa ada hubungan

2. Hubungan Antara Dukungan Sosial Perawat dengan Perawatan Paliatif yang bermakna antara faktor fisik dengan perawatan paliatif pada pasien terminal di RSI Siti Khadijah Palembang tahun 2015. Hasił Odds Ratio juga diperoleh sebesar 10,556 artinya responden yang melakukan faktor fisik secara baik mempunyai peluang 10,5 kali dibandingakan dengan responden yang melakukan faktor fisik kurang baik terhadap perawatan paliatif pada pasien terminal.

Tabel 5.6 Hubungan Antara Dukungan Sosial dengan Perawatan Paliatif pada Pasien Terminal

\begin{tabular}{|c|c|c|c|c|c|c|c|c|}
\hline \multirow{3}{*}{$\begin{array}{c}\text { Dukungan } \\
\text { Sosial }\end{array}$} & \multicolumn{4}{|c|}{ Perawatan Paliatif } & \multicolumn{2}{|c|}{ Total } & \multirow[t]{2}{*}{$\begin{array}{c}P \\
\text { Value }\end{array}$} & \multirow[t]{2}{*}{ OR } \\
\hline & \multicolumn{2}{|c|}{ Baik } & \multicolumn{2}{|c|}{ Kurang } & & & & \\
\hline & $n$ & $\%$ & $\mathrm{n}$ & $\%$ & $\mathrm{n}$ & $\%$ & & \\
\hline Baik & 19 & 82,6 & 4 & 17,4 & 23 & 100 & 0,018 & 7,125 \\
\hline Kurang & 6 & 40,0 & 9 & 60,0 & 15 & 100 & & \\
\hline & 25 & & 13 & & 38 & & & \\
\hline
\end{tabular}


Berdasarkan tabel 5.6 diatas dapat diketahu bahwa responden yang memberikan dukungan sosial baik dan melakukan perawatan paliatif secara baik sebanyak 19 responden $(82,6 \%)$ dari 23 responden sedangkan responden yang memberikan dukungan sosial kurang baik dan melakukan perawatan paliatif secara baik sebanyak 6 responden $(40,0 \%)$ dari 15 responden.

Hasiluji statistik didapatkan $p$ value 0,018 $<\alpha=0,05$ menunjukkan bahwa ada hubungan

3. Hubungan Antara Dukungan Spiritual Perawat dengan Perawatan Paliatif yang bermakna antara dukungan sosial dengan perawatan paliatif pada pasien terminal di RSI Siti Khadijah Palembang tahun 2015. Hasil Odds Ratio juga diperoleh sebesar 7,125 artinya responden yang melakukan dukungan sosial secara baik mempunyai peluang 7,1 kali dibandingakan dengan responden yang melakukan dukungan sosial kurang baik terhadap perawatan paliatif pada pasien terminal.

Tabel 5.7 Hubungan Antara Dukungan Spiritual dengan Perawatan Paliatif pada Pasien Terminal

\begin{tabular}{|c|c|c|c|c|c|c|c|c|}
\hline \multirow{3}{*}{$\begin{array}{c}\text { Dukungan } \\
\text { spiritual }\end{array}$} & \multicolumn{4}{|c|}{ Perawatan Paliatif } & \multicolumn{2}{|c|}{ Total } & \multirow[t]{2}{*}{$\begin{array}{c}P \\
\text { Value }\end{array}$} & \multirow[t]{2}{*}{ OR } \\
\hline & \multicolumn{2}{|c|}{ Baik } & \multicolumn{2}{|c|}{ Kurang } & & & & \\
\hline & $n$ & $\%$ & $n$ & $\%$ & $n$ & $\%$ & & \\
\hline Baik & 20 & 80,0 & 5 & 20,0 & 25 & 100 & 0,028 & 6,400 \\
\hline Kurang & 5 & 38,5 & 8 & 61,5 & 13 & 100 & & \\
\hline & 25 & & 13 & & 38 & & & \\
\hline
\end{tabular}

Berdasarkan tabel 5.7 diatas dapat diketahui bahwa responden yang memberikan dukungan spiritual baik dan melakukan perawatan paliatif secara baik sebanyak 20 responden $(80,0 \%)$ dari 25 responden sedangkan responden yang memberikan dukungan spiritual kurang baik dan melakukan perawatan paliatif secara baik sebanyak 5 responden $(38,5 \%)$ dari 13 responden.

Hasiluji statistik didapatkan $p$ value 0,028 $<a=0,05$ menunjukkan bahwa ada hubungan yang bermakna antara dukungan spiritual dengan perawatan paliatif pada pasien terminal di RSI Siti Khadijah Palembang tahun 2015. Hasil Odds Ratio juga diperoleh sebesar 6,400 artinya responden yang melakukan dukungan spiritual secara baik mempunyai peluang 6,4 kali dibandingakan dengan responden yang melakukan dukungan spiritual kurang baik terhadap perawatan paliatif pada pasien terminal.

\section{PEMBAHASAN}

1. Hubungan Antara Faktor Fisik dengan Perawatan Paliatif pada Pasien Terminal.

Berdasarkan hasil penelitian, responden yang memberikan faktor fisik baik dan melakukan perawatan paliatif secara baik sebanyak 19 responden $(86,4 \%)$ dari 22 responden sedangkan responden yang memberikan faktor fisik kurang baik dan melakukan perawatan paliatif secara baik sebanyak 6 responden $(37,5 \%)$ dari 16 responden. Hasiluji statistik didapatkan $p$ value $0,005<a=0,05$ menunjukkan bahwa ada 
hubungan yang bermakna antara faktor fisik dengan perawatan paliatif pada pasien terminal di RSI Siti Khadijah Palembang tahun 2015. Hasil Odds Ratio juga diperoleh sebesar 10,556 artinya responden yang melakukan faktor fisik secara baik mempunyai peluang 10,5 kali dibandingakan dengan responden yang melakukan faktor fisik kurang baik terhadap perawatan paliatif pada pasien terminal.

Hasil penelitian ini sejalan dengan teori yang dikemukakan Hastings (2006), perawatan fisik tetap memegang peranan sangat penting dan dapat sangat dibutuhkan seiring dengan menurunnya kondisi penderita, perawatan pada posisi apapun, yang paling nyaman buat penderita, tetaplah memandikan individu yang menjelang ajal, hal ini membantu penderita merasa nyaman dan dirawat dengan baik, menjelaskan tentang sesuatu yang sedang anda lakukan kepada penderita, hindari berbicara seakan-akan ia tidak ada disana dan pertahankan ruangan penderita tetap terang dan terventilasi, Walaupun penderita mungkin tampak hampir tidak sadar, pada kenyataannya ia dapat lebih sadar.

Hasil penelitian ini juga sejalan dengan penelitian Wira (2011), Pengukuran kebutuhan fisik trerhadap perawatan paliatif pada responden, diperoleh responden dengan kebutuhan fisik perawatan paliatif rendah (skor $\leq 400$ ) sebanyak 14 orang (16,5\%), sedang (skor 401-1000) sebanyak 65 orang (76,5\%), dan tinggi (skor > 900) sebanyak 6 orang $(7,1 \%)$.

Berdasarkan hasil penelitian, teori dan penelitian terkait yang ada maka peneliti berasumsi bahwa faktor fisik seperti mengatur posisi yang nyaman pada pasien, memandikan pasien walaupun kondisi pasien tidak sadar/lemah, selalu mengobservasi reaksi pasien memegang peranan sangat penting dan dibutuhkan pasien seiring menurunnya kondisi agar pasien merasakan nyaman dan merasa dirawat dengan baik sehingga penderitaan pasien dapat dikurangi.

2. Hubungan Antara Dukungan Sosial dengan Perawatan Paliatif pada Pasien Terminal.

Berdasarkan hasil penelitian, responden yang memberikan dukungan sosial baik dan melakukan perawatan paliatif secara baik sebanyak 19 responden $(82,6 \%)$ dari 23 responden sedangkan responden yang memberikan dukungan sosial kurang baik dan melakukan perawatan paliatif secara baik sebanyak 6 responden $(40,0 \%)$ dari 15 responden. Hasil uji statistik didapatkan $p$ value $0,018<\alpha=0,05$ menunjukkan bahwa ada hubungan yang bermakna antara dukungan sosial dengan perawatan paliatif pada pasien terminal di RSI Siti Khadijah Palembang tahun 2015. Hasil Odds Ratio juga diperoleh sebesar 7,125 artinya responden yang melakukan dukungan sosial secara baik mempunyai peluang 7,1 kali dibandingakan dengan responden yang melakukan dukungan sosial kurang baik terhadap perawatan paliatif pada pasien terminal.

Hasil penelitian ini sejalan dengan teori yang dikemukakan Ratna (2010), Dukungan sosial dapat diberikan oleh siapa saja dalam bentuk apa saja sebagai inplikasi dari adanya interaksi antar umat manusia. Semakin dalam interaksi dan hubungan emosi diantara keduanya, semakin besar dukungan yang dapat diberikan.

Hasil penelitian ini juga sejalan dengan penelitian Baskoro (2012), Berdasarkan analisis bivariat dengan menggunakan uji chi 
square terhadap dukungan keluarga dengan kualitas hidup pasien kanker yang menjalani kemoterapi di RSUD kraton Pekalongan didapatkan nilai $\rho$ value $=0,014$. Dengan demikian $\rho$ value $<\alpha(0,05)$ sehingga Ho ditolak, hal ini menunjukkan ada hubungan yang signifikan antara dukungan keluarga dengan kualitas hidup pasien kanker yang menjalani kemoterapi di RSUD Kraton Pekalongan.

Berdasarkan hasil penelitian, teori, dan penelitian terkait yang ada maka peneliti berasumsi bahwa jika perawat selalu memberikan pujian, bersikap halus dan melibatkan pasien dalam setiap kegiatan, terutama dalam pengobatan pada dirinya maka dapat meningkatkan kualitas hidup yang optimal pada pasien dan mampu menghadapi stress fisik maupun mental yang timbul dari luar maupun dari lingkungannya sendiri. Lingkungan sosial merupakan hubungan individu yang saling mempengaruhi.

\section{Hubunga Antara Dukungan Spiritual dengan}

Perawatan Paliatif pada Pasien Terminal.

Berdasarkan hasil penelitian, responden yang memberikan dukungan spiritual baik dan melakukan perawatan paliatif secara baik sebanyak 20 responden $(80,0 \%)$ dari 25 responden sedangkan responden yang memberikan dukungan spiritual kurang baik dan melakukan perawatan paliatif secara baik sebanyak 5 responden $(38,5 \%)$ dari 13 responden. Hasil uji statistik didapatkan $p$ value $0,028<\alpha=0,05$ menunjukkan bahwa ada hubungan yang bermakna antara dukungan spiritual dengan perawatan paliatif pada pasien terminal di RSI Siti Khadijah Palembang tahun 2015. Hasil Odds Ratio juga diperoleh sebesar
6,400 artinya responden yang melakukan dukungan spiritual secara baik mempunyai peluang 6,4 kali dibandingakan dengan responden yang melakukan dukungan spiritual kurang baik terhadap perawatan paliatif pada pasien terminal.

Hasil penelitian ini sejalan dengan teori Potter \& Perry (2005) menyatakan perawat dapat memberikan pemenuhan kebutuhan spiritualitas kepada pasien dengan memberikan dukungan emosional, membantu dan mengajarkan doa, memotivasi dan mengingatkan waktu ibadah sholat, mengajarkan relaksasi dengan berzikir ketika sedang kesakitan, berdiri didekat pasien, memberikan sentuhan selama perawatan.

Hasil penelitian ini sejalan dengan penelitian Grace (2010) yang menunjukkan bahwa ada hubungan peran perawat dalam pemberian terapi spiritual terhadap perilaku pasien dalam pemenuhan kebutuhan spiritual di ruang ICU Rumah Sakit Ahmad Dahlan kota Kediri, dari 20 responden sebagian besar memiliki kebiasaan spiritual berdoa yaitu sebanyak 13 responden (65\%) dan peran perawat paling banyak termasuk kategori baik dengan perilaku pasien dalam pemenuhan kebutuhan spiritual termasuk kategori baik yaitu sebanyak 13 responden (65\%).

Berdasarkan hasil penelitian, teori, dan penelitian terkait yang ada maka peneliti berpendapat bahwa salah satu peran perawat membimbing rohani pasien yang merupakan bentuk pelayanan kesehatan. Ini berarti perawatan paliatif dipengaruhi oleh dukungan spiritual seperti membantu pasien beribadah, memotivasi pasien untuk berdoa dan menggunakan waktu lebih banyak untuk mendekatkan diri pada Tuhan dapat membantu memberikan ketenangan pada diri pasien dan 
ketenangan yang paling besar adalah bersama Tuhan.

\section{KESIMPULAN}

1. Hasil distribusi dari 38 responden diketahui bahwa perawat yang melakukan perawatan paliatif dengan kategori baik sebanyak 25 responden (65,8\%), Responden yang melakukan faktor fisik dengan kategori baik sebanyak 22 responden (57,9\%), Responden yang melakukan dukungan sosial dengan kategori baik sebanyak 23 responden $(60,5 \%)$, Dan responden yang melakukan dukungan spiritual dengan kategori baik sebanyak 25 responden (65,8\%).

2. Ada hubungan antara faktor fisik dengan perawatan paliatif pada pasien terminal di RSI Siti Khadijah Palembang $(P$ value $=$ 0,005).

3. Ada hubungan antara dukungan sosial dengan perawatan paliatif pada pasien terminal di RSI Siti Khadijah Palembang ( $P$ value $=0,018$ )

4. Ada hubungan antara dukungan spiritual dengan perawatan paliatif pada pasien terminal di RSI Siti Khadijah Palembang ( $P$ value $=0,028$ )

\section{SARAN}

1. Bagi Institusi Rumah Sakit

Hasil penelitian ini diharapkan dapat memberikan informasi yang berguna bagi Rumah Sakit terutama bagi perawat sebagai masukkan dan pertimbangan dalam melakukan tindakan asuhan keperawatan terutama pada pasien terminal.

2. Bagi Institusi Pendidikan
Hendaknya diperpustakaan melengkapi buku-buku khusus yang berkaitan dengan pasien terminal, guna mempermudah mahasiswa dalam mencari referensi untuk penelitian dan mempelajari masalah perawatan paliatif pada pasien terminal.

\section{Bagi Peneliti Selanjutnya \\ Hasil penelitian ini dapat ditingkatkan menjadi rancangan yang lebih tinggi seperti dengan menggunakan cara penelitian wawancara dan observasi dengan menggunakan sampel yang berbeda serta variabel yang berbeda agar didapat hasil yang berarti.}

\section{DAFTAR PUSTAKA}

Ahmadi. 2007. Keperawatan Pasien di Ruang ICU. Jakarta: Rineka Cipta.

Ambarwati, Eny R. 2011. KDPK Kebidanan Teori \& Aplikasi. Yogyakarta: Nuha Medika.

Black,J.M.,and Hawks,J.H. 2005. Medical Surgical Nursing Clinical Management for PositiveOutcomes.Philadelphi: WB Saunders.

Boyle P. 2008. World Cancer Report 2008. Lyon (Prancis): International Agency for Research on Cancer.

Burton C.R,et al, 2010. The Palliative Care Needs of Cancer Patiens. A Prospective Study of Hospital Admissions.

Chusairi Achmad. 2009. Health Seeking Behavior Para Pasien Poli Perawatan Paliatif RSUD dr. Soetomo Surabaya. Jurnal Universitas Airlangga Surabaya 2009.

Counsel and Care. 2008. Terminal Illnes-Caring and Coping. London: Twyman House.

Doyle, Hanks and Macdonald, 2003. Oxford Textbook of Palliative Medicine. Oxford Medical Publications (OUP) 3rd end 2003. 
Elmeida, Ika F. 2012. Keterampilan Dasar Kebidanan. Jakarta: TIM.

Hastings, Diana. 2006. Pedoman Keperawatan di Rumah. Jakarta: EGC.

Hidayat, A. Aziz Alimul. 2014. Metode Penelitian Kebidanan dan Teknik Analisa Data. Jakarta: Salemba Medika.

2009. Kebutuhan

Dasar Manusia. Jakarta: EGC.

Kementerian Kesehatan RI. 2007. Keputusan Menteri Kesehatan No 430/Menkes/SK/IV/2007

TentangPedoman Pengendalian

Penyakit Kanker. Jakarta: Kementerian Kesehatan.

Kemp Charles, 2010. Klien Sakit Terminal Edisi Jilid 2. Jakarta: EGC.

Kepmenkes

RI Nomor: 812/MENKES/SK/VII/2007 Tentang Kebijakan perawatan Palliative Menteri Kesehatan Republik Indonesia.

Kubler-Ross,E. On Death and Dying. London: Tavistock Publication.

Lewis, S.M., Heitkemper, M.M., \& Dirksen, S.R. 2004. Medical surgical nursing: Assessment and management of clinical problems. (6th ed). Mosby: Elsevier, Inc.

Megawe, Herlin. 1998. Nyeri Kanker. Surabaya: Media IDI.

Mubarak Wahid, 2008. Kebutuhan dasar Manusia: Teori \& Aplikasi dalam Praktik. Jakarta: EGC.

Notoadmojdo. 2012. Metodelogi Penelitian Kesehatan. Jakarta: Rineka Cipta.

Nuhonni, S.A. 2010. Kembang Rampai Perawatan Paliatif. Fakultas Kedokteran Universitas Indonesia. Jakarta.

Nursalam 2013. Konsep dan Penerapan Metodelogi Penelitian IImu Keperawatan Edisi Jilid 3: Salemba Medika.

Potter, Perry. 2000. Guide to Basic Skill and Prosedur Dasar, Edisi III, Alih bahasa Ester Monica, Penerbit buku kedokteran EGC. 2005. Fundamental of Nursing Concept, Process and Practice. Edisi 4. Jakarta: EGC.

2009. Fundamental of Nursing. Singapore: Mosbi Elsevier.
Pradana, Putu W. 2011. Hubungan Kualitas Hidup dengan Kebutuhan Perawatan Paliatif pada Pasien Kanker di RSUP Sanglah Denpasar. Jurnal Kedokteran Universitas Udayana Denpasar.

Profil Kesehatan. 2013. Profil Kesehatan Provinsi Sumsel Tahun 2013. Palembang.

2012. Profil Kesehatan Indonesia Tahun 2012. Jakarta: Kementrian Kesehatan RI.

Rasjidi. Imam. 2010. Perawatan Paliatif Suportif \& Bebas Nyeri Pada Kanker. Jakarta: CV Sagung Seto.

Ratna, Wahyu, 2010. Sosiologi dan Antropologi Kesehatan dalam Perspektif IImu Keperawatan. Jakarta: Pustaka Rihama.

Tejawinata. Sunaryadi, 2008, Perawatan Paliatif adalah Hak Asasi Setiap Manusia. Jakarta: EGC

Waller et al. 2011. Development of a Palliative Care Needs Assessment Tool (PCNAT) for Use by Multi-Disciplinary Health Professionals. Centre For Health Research \& PsychoOncology.

White,PG. 2002. Word Hospice Palliative Care The Loss of Child Day, Pediatric Heart Network.www.hospiceinternational.com 